\title{
Case Report of Cirrhosis following Yttrium-90 Radioembolization for Pancreatic Neuroendocrine Liver Metastases
}

\author{
Jonathan M. Loree ${ }^{a} \quad$ Tadaaki Hiruki $^{b}$ Hagen F. Kennecke ${ }^{a}$ \\ aDivision of Medical Oncology and ${ }^{\mathrm{b}}$ Department of Pathology, BC Cancer Agency, \\ Vancouver, B.C., Canada
}

\section{Key Words}

Fibrosis · Microspheres · Liver disease · Toxicity · Radiation

\begin{abstract}
Background: Management options for pancreatic neuroendocrine tumors (pNETs) metastatic to the liver include surgical, ablative, cytotoxic, and radioisotope approaches. One potential local treatment option includes selective internal radiotherapy utilizing yttrium-90 $\left({ }^{90} \mathrm{Y}\right)$ microspheres. ${ }^{90} \mathrm{Y}$ has also been used in the treatment of hepatocellular carcinoma and tumors metastatic to the liver. It appears to be well tolerated; however, there is no randomized controlled trial reporting long-term toxicities. Previous retrospective reports have described biliary damage as a potential complication of therapy with ${ }^{90} \mathrm{Y}$ and chemoembolization; however, the long-term sequelae of ${ }^{90} \mathrm{Y}$ treatment are poorly understood. Case Presentation: We present the case of a 65-year-old Caucasian woman who suffered biliary damage following ${ }^{90} \mathrm{Y}$ administration for metastatic pNETs and subsequently developed cirrhosis. Given the timeline of her various treatments and the lack of any other identifiable etiology for her cirrhosis, we believe this to be a potential long-term complication of ${ }^{90} \mathrm{Y}$ therapy. Conclusion: This case provides pathologic confirmation of cirrhosis as a potential long-term sequela of ${ }^{90} \mathrm{Y}$ treatment. This long-term risk needs to be considered when sequencing therapy for patients with neuroendocrine tumors who have a good prognosis. There are now several other systemic and ablative treatment options available to these patients, and long-term complications must be considered during treatment.


Loree et al.: Case Report of Cirrhosis following Yttrium-90 Radioembolization for Pancreatic Neuroendocrine Liver Metastases

\section{Introduction}

Pancreatic neuroendocrine tumors (pNETs) represent a relatively uncommon form of malignancy with an incidence of 0.43 cases per 100,000 in the USA [1]. At diagnosis, nearly $70 \%$ of patients have metastatic disease, of which $85 \%$ will have liver metastases [2]. Management options for pNETs metastatic to the liver include surgical, ablative, cytotoxic, and radioisotope approaches. Unfortunately, due to the scarcity of these tumors there is a paucity of randomized trials to guide optimal therapy sequencing. The North American Neuroendocrine Tumor Society and European Neuroendocrine Tumor Society both support the use of radioembolization for progressive or symptomatic liver metastasis [3, 4]. To date, yttrium-90 $\left({ }^{9} \mathrm{Y}\right)$ therapy has appeared safe; however, there is no randomized controlled trial assessing toxicities [5]. We present the case of a woman undergoing ${ }^{90} \mathrm{Y}$ therapy for metastatic pNET to the liver who developed liver enzyme elevation and subsequent cirrhosis following treatment. There are only 3 other reported de novo cases of cirrhosis following ${ }^{90} \mathrm{Y}$ administration, with only 1 demonstrating confirmatory pathology [6-8].

\section{Case Report}

A 65-year-old woman presented with abdominal discomfort and decreased appetite. Ultrasonography and computed tomography (CT) of the abdomen revealed a $9.5 \times 8.6 \times 10.5$ $\mathrm{cm}$, heterogeneous, hypervascular mass adjacent to the spleen and abutting the stomach wall and tail of the pancreas. Fine-needle aspiration guided by endoscopic ultrasound revealed cytologic evidence of a neuroendocrine tumor. The patient proceeded to a distal pancreatectomy, splenectomy, wedge resection of the stomach, and partial resection of the left adrenal gland. Pathology demonstrated a $13-\mathrm{cm}$, well-differentiated neuroendocrine tumor of the pancreas with perineural invasion, but no vascular invasion and negative margins. It was found to be adherent to both the spleen and the stomach, but did not invade either. Two lymph nodes were removed, and both were negative for metastases. It had a mitotic rate of 2 mitoses/high-power field and a Ki-67 index of $<2 \%$. There were no signs of metastatic disease on staging.

Two months postoperatively, the patient was found to have 4 subcentimeter hypervascular lesions in the liver which were ${ }^{111}$ In octreotide scan negative. Over the following 9 months, the patient developed 8 new lesions, while the original lesions increased to a maximum size of $1.2 \mathrm{~cm}$. Therapy with octreotide LAR $20 \mathrm{mg}$ intramuscularly once monthly was initiated but discontinued after 9 months due to progressive hepatic disease. The patient subsequently underwent a bland embolization of the right hepatic artery. A CT scan of the liver performed 3 months after embolization demonstrated a mixed tumor response with the overall impression of progressive disease and development of new liver metastasis.

The patient was presented with the option of systemic therapy with everolimus, shown in phase III trials to improve progression-free survival in patients with well-differentiated pNETs [9]. Due to the absence of extrahepatic metastasis, liver-directed therapy with ${ }^{90} \mathrm{Y}$ embolization was also offered, which the patient chose to proceed with. Prior to ${ }^{90} \mathrm{Y}$ treatment, there was no radiologic evidence of cirrhosis and the liver enzymes were within normal ranges (AST $24 \mathrm{U} / \mathrm{l}$ [normal range $(\mathrm{N})$ 10-38 U/l], ALT $36 \mathrm{U} / \mathrm{l}[\mathrm{N}<50 \mathrm{U} / \mathrm{l}]$, alkaline phosphatase $156 \mathrm{U} / \mathrm{l}[\mathrm{N} \mathrm{50-200} \mathrm{U/l]}$, total bilirubin $5 \mu \mathrm{mol} / \mathrm{l}[\mathrm{N} 0-18 \mu \mathrm{mol} / \mathrm{l}])$. She had a technetium-99 macroaggregate albumin planning SPECT CT demonstrating multiple focal regions of increased activity in the left and right lobes of the liver which corresponded to the patient's known metastases. 
Loree et al.: Case Report of Cirrhosis following Yttrium-90 Radioembolization for Pancreatic Neuroendocrine Liver Metastases

Radioembolization with $3.5 \mathrm{GBq}$ of ${ }^{90} \mathrm{Y}$ TheraSpheres ${ }^{\circledR}$ was administered to the right hepatic artery, delivering a total dose of $140 \mathrm{~Gy}$ to the right lobe of the liver, and $1.8 \mathrm{GBq}$ of ${ }^{90} \mathrm{Y}$ TheraSpheres ${ }^{\circledR}$ was delivered through the left hepatic artery with a dosing of 140 Gy to the left lobe of the liver on the same day. Over the following 3 months, the patient developed abdominal pain and nausea and was found to have elevated liver enzymes, in a pattern suggesting damage to the biliary tree (AST $52 \mathrm{U} / \mathrm{l}$, ALT $86 \mathrm{U} / \mathrm{l}$, alkaline phosphatase $405 \mathrm{U} / \mathrm{l}$, GGT $604 \mathrm{U} / \mathrm{l}$, total bilirubin $5 \mu \mathrm{mol} / \mathrm{l})$. CT scanning of the abdomen demonstrated generalized mottling of the liver, compatible with postembolization edema with a substantial decrease in tumor burden and 2 significant lesions remaining. A repeat ${ }^{90} \mathrm{Y}$ radioembolization focused on the residual lesions was not technically feasible. The patient's liver enzymes remained elevated over the following 6 months until she developed significant right upper quadrant pain. CT 9 months after ${ }^{90} \mathrm{Y}$ treatment revealed a very inhomogeneous liver texture and a large biloma traversing segments 5 and 8 of the liver, measuring $8.5 \times 6.5 \times 5.5 \mathrm{~cm}$. A radiographic impression of liver surface nodularity was noted. This was initially noted 10 months after ${ }^{90} \mathrm{Y}$ treatment and was slightly progressive on the 14-month scan (fig. 1). Imaging also demonstrated multiple subcentimeter right hepatic lesions raising concern for metastatic disease, some of which had not previously been seen.

Due to radiographic evidence of progressive disease, everolimus $10 \mathrm{mg}$ once daily was initiated, and the patient continued on this for 36 months with stabilization of the disease. Her liver enzymes remained unchanged over this time, with elevated hepatobiliary enzymes and borderline-elevated hepatocellular enzymes. At 25 months after initiation of everolimus therapy, progressive disease was noted in 2 solitary hepatic lesions and was treated with radiofrequency ablation. Due to disease control in the remainder of the hepatic parenchyma, everolimus was resumed after radiofrequency ablation.

Thirty-five months after initiation of everolimus therapy, radiographic note was made of the advanced cirrhotic appearance of the liver (fig. 1) and the increase in size of a left hepatic lesion. There was no evidence of portal hypertension. Due to the radiographic evidence of progressive disease and the cirrhotic appearance of the liver, everolimus therapy was interrupted and a liver biopsy to further characterize the nature of the parenchymal disease was performed. A single 18-gauge core was obtained from the left lobe of the liver in order to avoid the biloma involving the right lobe. Non-tumor-containing tissue was biopsied. The biopsy demonstrated large fibrotic bands in keeping with cirrhosis with mildly active steatohepatitis (approx. 10\% macrovesicular steatosis) (fig. 2).

The patient had not been started on any other new medications, did not drink alcohol excessively, performed no high-risk activities for viral hepatitis, and had no family history of liver disease. Serology was nonreactive for $\mathrm{HB}_{\mathrm{S}} \mathrm{Ag}, \mathrm{HB}_{\mathrm{C}} \mathrm{Ab}$, and hepatitis $\mathrm{C}$ virus, and the patient had immunity to hepatitis B virus. Her antinuclear antibody was equivocal, and her anti-smooth muscle antibody and antimitochondrial antibody were negative. Given the chronologic association of ${ }^{90} \mathrm{Y}$ administration with liver enzyme elevation, with the exclusion of other causes of cirrhosis, the diagnosis of ${ }^{90} \mathrm{Y}$-induced cirrhosis was made. She has not suffered any cirrhosis-associated complications and is currently Child-Turcotte-Pugh class A.

\section{Discussion}

To date, ${ }^{90}$ Y-related cirrhosis has only been reported in 3 cases [6-8]. A prior systematic review assessing outcomes following ${ }^{90} \mathrm{Y}$ radioembolization identified grade 3 and higher adverse events in $0-12.9 \%$ of patients. In their review, the authors were able to identify 1 episode of cirrhosis and 3 episodes of hepatic failure [5]. The 3 cases of hepatic failure were 
Loree et al.: Case Report of Cirrhosis following Yttrium-90 Radioembolization for Pancreatic Neuroendocrine Liver Metastases

reported with no mention of cirrhosis. The 1 cirrhotic patient identified was seen by Saxena et al. [6], who described a patient with cirrhosis and ascites 6 months after treatment with grade 3 elevation of serum alkaline phosphatase and grade 2 elevations of ALT and bilirubin. It is unclear whether the patient had tissue biopsy confirmation of cirrhosis.

Other reported cases of cirrhosis come from case reports by Brock et al. [7] and Ayav et al. [8]. Brock et al. [7] described a patient with metastatic breast cancer with bone and liver metastases who received ${ }^{90} \mathrm{Y}$. The patient had a good response to treatment at 4 weeks, but 3 months later developed CT imaging findings consistent with cirrhosis and portal hypertension. The patient subsequently died. There was no tissue biopsy. Ayav et al. [8] described a 39 -year-old man who received ${ }^{90} \mathrm{Y}$ for colon carcinoma metastatic to the liver. Four months after administration, the patient was found to have signs of portal hypertension and had a biopsy consistent with cirrhosis. The timeline of initial hepatic changes seen with our patient closely resembles these previous reports, with a subacute onset of irregular echotexture and cirrhosis occurring several months following treatment with ${ }^{90} \mathrm{Y}$ [6-8].

${ }^{90} \mathrm{Y}$ microspheres deliver focused radiotherapy to metastases in the liver while sparing viable hepatic tissue, due to the predominant arterial supply of hepatic metastases as compared to the predominantly portal venous blood supply of normal liver parenchyma. An assessment of explanted livers following ${ }^{90} \mathrm{Y}$ treatment showed no fibrosis $>1 \mathrm{~cm}$ from tumor borders [10]. The case of our patient adds to 3 previously reported cases that demonstrate cirrhosis as a potential long-term complication of ${ }^{90} \mathrm{Y}$ treatment. This is clinically relevant as it may influence therapy sequencing. Multiple ablative and systemic treatment options exist for patients with metastatic, unresectable pNETs. An increasingly long median life expectancy is observed with pNETs, with a 5-year overall survival of patients with lowgrade tumors of $75 \%$ [3]. Therapies with a significant rate of long-term toxicities should therefore be avoided early in the course of therapy among patients with advanced disease.

The notion that ${ }^{90} \mathrm{Y}$ therapy may lead to cirrhosis is supported by radiographic studies assessing volume changes and signs of portal hypertension following ${ }^{90} \mathrm{Y}$ treatment. In a series of 17 patients treated with ${ }^{90} \mathrm{Y}$, a mean decrease in liver volume of $11.8 \%$ and a mean increase in splenic volume of $27.9 \%$ were noted, accompanied by increases in portal vein diameter [11]. In another series of 45 patients, liver volumes were shown to decrease in lobes treated with radioembolization by up to $45 \%$ at 12 months after treatment [12]. The difficulty with utilizing volume changes and liver texture to define outcomes following ${ }^{90} \mathrm{Y}$ administration lies in differentiating normal radiographic changes following radioembolization from true cirrhosis. In the current case report, imaging was reported as being consistent with prior radioembolization throughout many of the reports, with a progressive worsening noted over time. While differentiating this from cirrhosis is very difficult, the differential for these radiographic changes needs to include cirrhosis.

The only other agent that could be chronologically associated with cirrhosis in our patient is everolimus; however, this was started after radiographic changes had already been seen in the liver. In addition, early preclinical work suggests that inhibition of the mTOR pathway with mTOR inhibitors may be antifibrotic [13]. There is, however, 1 case report of steatohepatitis following administration of everolimus [14]. While our patient did not have steatosis severe enough to be considered solely responsible for the observed cirrhosis, it is possible that she suffered an initial insult from ${ }^{90} \mathrm{Y}$ administration and had impaired hepatic regeneration subsequently due to everolimus-induced steatosis, thus causing accelerated progression to cirrhosis.

In addition to cirrhosis, our patient suffered a second complication of ${ }^{90} \mathrm{Y}$ administration. She developed a large biloma 10 months following ${ }^{90} \mathrm{Y}$ treatment. In a 327-patient retrospective review by Atassi et al. [15], 10.1\% of patients had developed some form of biliary 
Loree et al.: Case Report of Cirrhosis following Yttrium-90 Radioembolization for Pancreatic Neuroendocrine Liver Metastases

complication following ${ }^{90} \mathrm{Y}$ administration. In contrast to normal hepatocytes, intrahepatic bile ducts lack a dual blood supply and are fed by intrahepatic arteries. Biloma development is thought to develop following peripheral bile duct necrosis, resulting in biliary drainage into surrounding tissue. The damage can range from mild bile duct dilation to severe strictures. Most of these lesions remain stable, with minimal intervention required.

\section{Conclusions}

This case report adds to a growing body of evidence that ${ }^{90} \mathrm{Y}$ treatment may cause serious damage to the biliary tree, and it is clinically important because it demonstrates pathology confirming that a long-term outcome of ${ }^{90} \mathrm{Y}$ administration may be cirrhosis. This longterm risk needs to be considered when sequencing therapy for patients who have a high rate of 5-year survival and who have other systemic and ablative treatment options.

\section{Statement of Ethics}

Written informed consent was obtained from the patient for publication of this case report.

\section{Disclosure Statement}

All authors report no conflicts of interest.

\section{References}

1 Lawrence B, Gustafsson BI, Chan A, Svejda B, Kidd M, Modlin IM: The epidemiology of gastroenteropancreatic neuroendocrine tumors. Endocrinol Metab Clin North Am 2011;40:1-18, vii.

-2 Pape U-F, Berndt U, Müller-Nordhorn J, Böhmig M, Roll S, Koch M, et al: Prognostic factors of long-term outcome in gastroenteropancreatic neuroendocrine tumours. Endocr Relat Cancer 2008;15:1083-1097.

-3 Pavel M, Baudin E, Couvelard A, Krenning E, Öberg K, Steinmüller T, et al: ENETS Consensus Guidelines for the management of patients with liver and other distant metastases from neuroendocrine neoplasms of foregut, midgut, hindgut, and unknown primary. Neuroendocrinology 2012;95:157-176.

-4 Kulke MH, Anthony LB, Bushnell DL, de Herder WW, Goldsmith SJ, Klimstra DS, et al: NANETS treatment guidelines: well-differentiated neuroendocrine tumors of the stomach and pancreas. Pancreas 2010;39:735-752.

-5 Yang TX, Chua TC, Morris DL: Radioembolization and chemoembolization for unresectable neuroendocrine liver metastases - a systematic review. Surg Oncol 2012;21:299-308.

-6 Saxena A, Chua TC, Bester L, Kokandi A, Morris DL: Factors predicting response and survival after yttrium90 radioembolization of unresectable neuroendocrine tumor liver metastases: a critical appraisal of 48 cases. Ann Surg 2010;251:910-916.

7 Brock H, Günther RW, Haage P: Liver cirrhosis as sequela of selective hepatic radio-embolization with yttrium (Y-90) microspheres (in German). Rofo 2006;178:546-548.

8 Ayav A, Habib N, Jiao LR: Portal hypertension secondary to ${ }^{90}$ Yttrium microspheres: an unknown complication. J Clin Oncol 2005;23:8275-8276.

-9 Yao JC, Shah MH, Ito T, Bohas CL, Wolin EM, Van Cutsem E, et al: Everolimus for advanced pancreatic neuroendocrine tumors. N Engl J Med 2011;364:514-523.

10 Kennedy AS, Nutting C, Coldwell D, Gaiser J, Drachenberg C: Pathologic response and microdosimetry of ${ }^{90} \mathrm{Y}$ microspheres in man: review of four explanted whole livers. Int J Radiat Oncol Biol Phys 2004;60:15521563. 


\section{Case Reports in Oncology}

\begin{tabular}{l|l}
\hline Case Rep Oncol 2016;9:76-82 \\
\hline DOI: 10.1159/000443985 & $\begin{array}{l}\text { (c) 2016 The Author(s). Published by S. Karger AG, Basel } \\
\text { www.karger.com/cro }\end{array}$ \\
\hline
\end{tabular}

Loree et al.: Case Report of Cirrhosis following Yttrium-90 Radioembolization for Pancreatic Neuroendocrine Liver Metastases

11 Jakobs TF, Saleem S, Atassi B, Reda E, Lewandowski RJ, Yaghmai V, et al: Fibrosis, portal hypertension, and hepatic volume changes induced by intra-arterial radiotherapy with ${ }^{90}$ Yttrium microspheres. Dig Dis Sci 2008;53:2556-2563.

-12 Theysohn JM, Ertle J, Müller S, Schlaak JF, Nensa F, Sipilae S, et al: Hepatic volume changes after lobar selective internal radiation therapy (SIRT) of hepatocellular carcinoma. Clin Radiol 2014;69:172-178.

-13 Neef M, Ledermann M, Saegesser H, Schneider V, Reichen J: Low-dose oral rapamycin treatment reduces fibrogenesis, improves liver function, and prolongs survival in rats with established liver cirrhosis. J Hepatol 2006;45:786-796.

14 Schieren G, Bölke E, Scherer A, Raffel A, Gerber PA, Kröpil P, et al: Severe everolimus-induced steatohepatis [sic!]: a case report. Eur J Med Res 2013;18:22.

15 Atassi B, Bangash AK, Lewandowski RJ, Ibrahim S, Kulik L, Mulcahy MF, et al: Biliary sequelae following radioembolization with yttrium-90 microspheres. J Vasc Interv Radiol 2008;19:691-697.
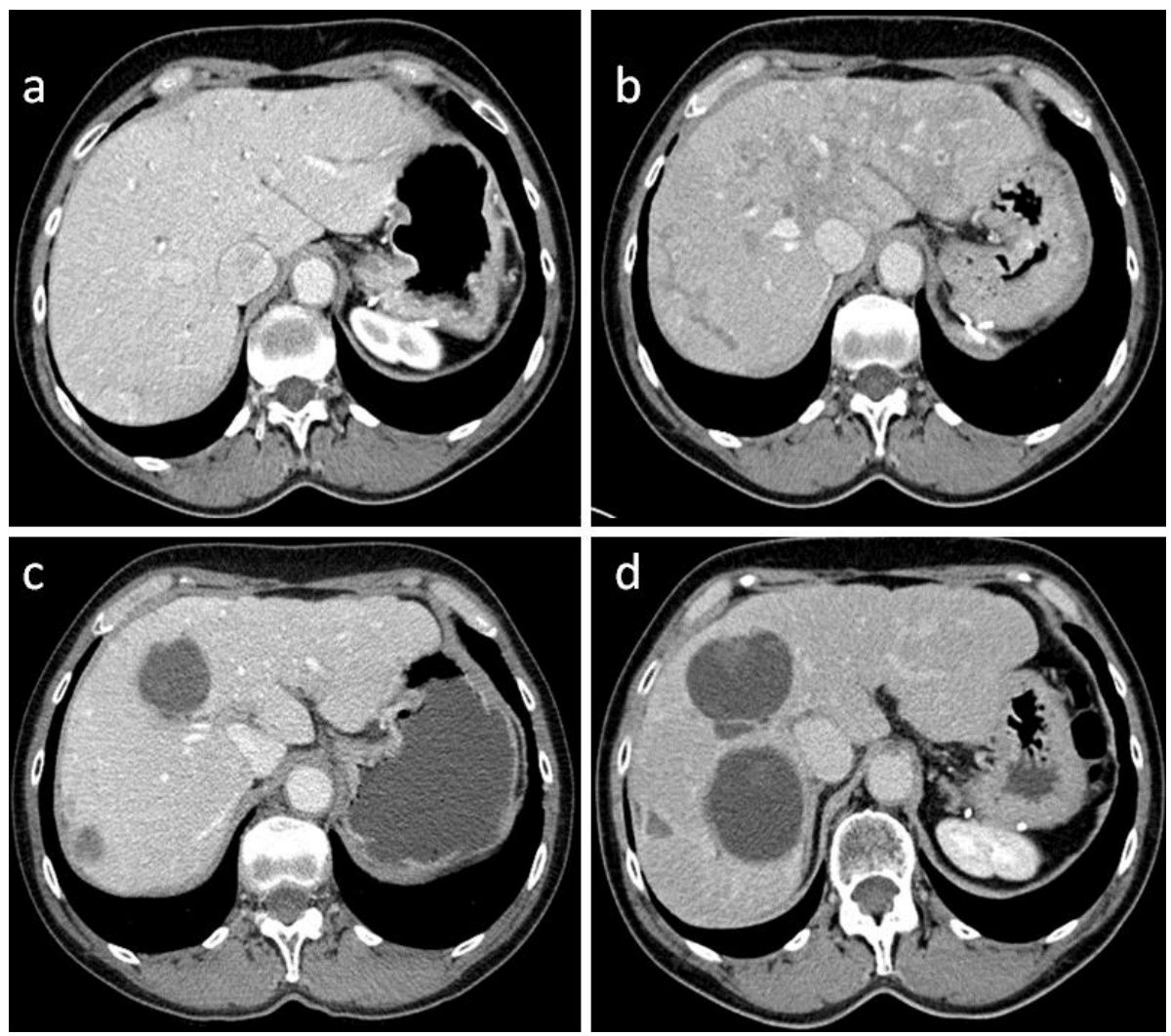

Fig. 1. Contrast-enhanced CT imaging demonstrating no cirrhotic changes prior to ${ }^{90} \mathrm{Y}$ administration (a) and generalized mottled changes compatible with postembolization edema 3 months after ${ }^{90} \mathrm{Y}$ administration (b). The patient subsequently developed a large, nonenhancing, complex cystic central hepatic lesion suggestive of a post-90Y biloma 14 months after administration (c) and over the subsequent 45 months developed a progressively irregular texture suggestive of hepatic cirrhosis (d). 


\section{Case Reports in Oncology}

\begin{tabular}{l|l}
\hline Case Rep Oncol 2016;9:76-82 \\
\hline DOI: 10.1159/000443985 & $\begin{array}{l}\text { (c) 2016 The Author(s). Published by S. Karger AG, Basel } \\
\text { www.karger.com/cro }\end{array}$ \\
\hline
\end{tabular}

Loree et al.: Case Report of Cirrhosis following Yttrium-90 Radioembolization for Pancreatic Neuroendocrine Liver Metastases
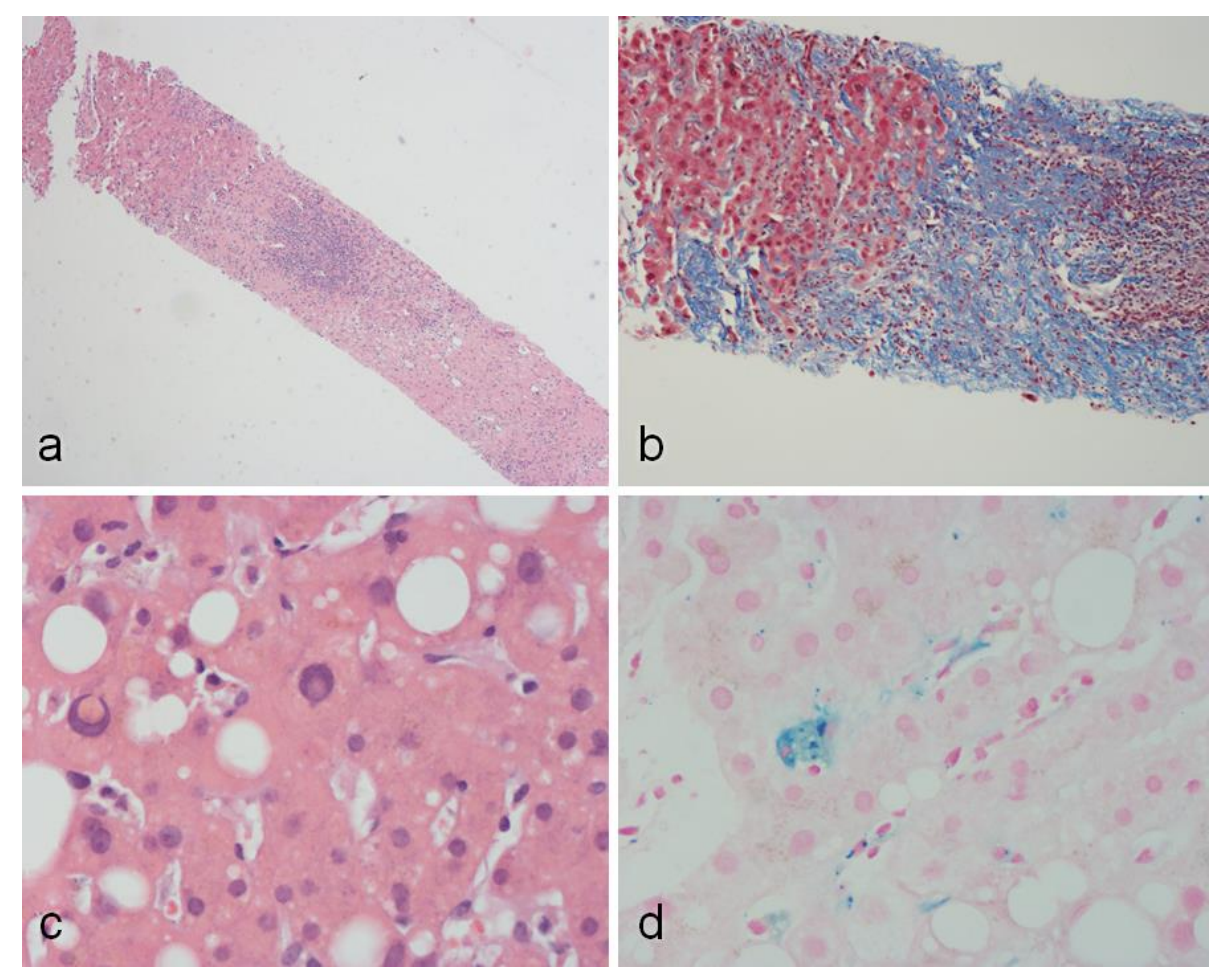

Fig. 2. Needle core biopsy of the liver taken 47 months after ${ }^{90} \mathrm{Y}$ administration. a There is a large band of chronically inflamed fibrous tissue, highly suggestive of cirrhosis. HE. $\times 10$. $\mathbf{b}$ This is highlighted by Masson trichrome staining, demonstrating chronically inflamed fibrous tissue (blue), highly suggestive of cirrhosis. $\times 10$. $\mathrm{c}$ The nonfibrotic liver showed macrovesicular steatosis with mildly active steatohepatitis. HE. $\times 40$. $d$ On the other hand, sinusoidal Kupffer cells showed a mild degree of hemosiderosis. Perls iron stain. $\times 40$. 